\title{
Temperature and pressure effect on the anisotropy of dielectric permeability in KDP and DKDP crystals
}

\author{
V.M.Kedyulich, A.G.Slivka, E.I.Gerzanich, A.M.Guivan, \\ P.M.Lukach \\ Uzhgorod National University, \\ 32 Voloshina Str., 88000 Uzhgorod, Ukraine
}

Received October 24, 2002, in final form April 4, 2003

\begin{abstract}
Temperature dependences of longitudinal and transverse dielectric permeability of KDP and DKDP crystals are studied at different values of hydrostatic pressure in order to determine the pressure behaviour of the isotropic point for these crystals. The isotropic point temperature in KDP crystals at atmospheric pressure is $T_{i}=186 \mathrm{~K}$ at the measuring field frequency $1 \mathrm{kHz}$ and $T_{i}=176 \mathrm{~K}$ at the frequency of $1 \mathrm{MHz}$. In DKDP crystals the isotropic point is achieved at the temperature $T_{i}=300 \mathrm{~K}(1 \mathrm{kHz})$ and $T_{i}=253 \mathrm{~K}(1 \mathrm{MHz})$. The hydrostatic pressure increase results in the reduction of the isotropic point temperature with the pressure coefficients $\partial T_{i} / \partial p=-4.3 \mathrm{~K} / \mathrm{kbar}$ for KDP and $\partial T_{i} / \partial p=-2.9 \mathrm{~K} / \mathrm{kbar}$ for DKDP. The analysis of the experimental results in the framework of the Blinc-Žekš pseudospin formalism has shown a good agreement between the calculated and the experimentally obtained temperature of the isotropic point for KDP crystals.
\end{abstract}

Key words: ferroelectrics, dielectric permeability, hydrostatic pressure, isotropic point

PACS: $77.80 . \mathrm{Bh}, 77.22 . \mathrm{Ch}, 77.84 . \mathrm{Fa}$

\section{Introduction}

$\mathrm{KH}_{2} \mathrm{PO}_{4}(\mathrm{KDP})$ and $\mathrm{KD}_{2} \mathrm{PO}_{4}(\mathrm{DKDP})$ crystals above the temperature of the ferroelectric first-order phase transition are tetragonal, while in the ferroelectric phase they are rhombic [1]. The anomalies of dielectric permeability, related to the phase transition, are observed both along the spontaneous polarization axis and normally to it due to a specific mechanism of the phase transition in these crystals. Proton ordering at hydrogenic bonds in the $a b$ plane causes the displacement of ions along the $c$ axis and the spontaneous polarization.

The temperature dependence of longitudinal (along the spontaneous polarization direction) dielectric permeability of both crystals in the paraelectric phase obeys the 
Curie-Weiss law [2]. In the ferroelectric phase a shoulder is observed in this plot, related to the effect of domain structure freezing [3,4]. The studies of hydrostatic pressure effect on the longitudinal dielectric permeability have shown that the increase of the all-round pressure causes the decrease of the phase transition temperatures with the coefficients $\partial T_{\mathrm{c}} / \partial p=-4.6 \mathrm{~K} / \mathrm{kbar}$ for $\mathrm{KDP}$ and $\partial T_{\mathrm{c}} / \partial p=-2.4 \mathrm{~K} / \mathrm{kbar}$ for DKDP [2] and the downward shift of the $\varepsilon_{c}(T)$ curves in the temperature scale. At the pressure near $18 \mathrm{kbar}$, the phase transition temperature in the KDP crystal is zero and the value $\partial T_{\mathrm{c}} / \partial p$ tends to infinity, while the $(p, T)$ phase diagram of the DKDP crystal is linear. Such a behaviour of the pressure variation of the phase transition temperature in KDP crystals is related to the proton tunnelling effect, and the increase of the hydrogen atom mass in DKDP crystals sharply decreases the tunnelling probability $[5,6]$.

The temperature dependence of transverse (normally to the spontaneous polarization axis) dielectric permeability in the KDP crystals at atmospheric pressure is given in [7]. At the phase transition temperature $T_{\mathrm{c}}=122 \mathrm{~K}$, the dependence $\varepsilon_{a}(T)$ reveals a step. Above the phase transition point in the paraelectric phase there is a maximum in the $\varepsilon_{a}(T)$ plot. The similar behaviour of the dielectric permeability was observed for antiferroelectric $\mathrm{KMnF}_{3}, \mathrm{NH}_{4} \mathrm{H}_{2} \mathrm{AsO}_{4}$ crystals [8].

The specific feature of the anisotropy of dielectric permeability in the paraelectric phase of KDP and DKDP crystals is the presence of an isotropic point where the longitudinal and transverse dielectric permeability values are equal [9]. At this point the crystals become isotropic with respect to the dielectric permeability $\varepsilon_{a}=\varepsilon_{b}=\varepsilon_{c}$. The aim of the present paper is to study the temperature dependences of longitudinal and transverse dielectric permeability of KDP and DKDP crystals at different values of external hydrostatic pressure as well as to trace the pressure behaviour of the isotropic point temperature.

\section{Results}

Figure 1 shows the temperature dependences of longitudinal and transverse dielectric permeability of KDP crystals at atmospheric pressure at the measuring field frequency $1 \mathrm{kHz}$ (curve 1) and $1 \mathrm{MHz}$ (curve 2). No dispersion of the transverse dielectric permeability at these frequencies has been found (curve 3). At the frequency of $1 \mathrm{kHz}$ the dependence of the longitudinal dielectric permeability has two anomalies: a maximum of $\varepsilon_{c}(T)$ at the phase transition temperature $T_{\mathrm{c}}=122 \mathrm{~K}$ and a shoulder in the ferroelectric phase in the temperature range from 91 to $122 \mathrm{~K}$, related to the domain structure transformation [4]. At the measuring field frequency of $1 \mathrm{MHz}$ a number of extrema is observed in the $\varepsilon_{c}(T)$ plot in the vicinity of the phase transition point (curve 2). Such feature is the evidence of the piezoelectric resonance in KDP crystals [10] and cannot be related to the order parameter relaxation time tending to infinity in the order/disorder-type ferroelectrics since in this case one minimum at the temperature dependence of the dielectric permeability should be observed at the phase transition temperature. 


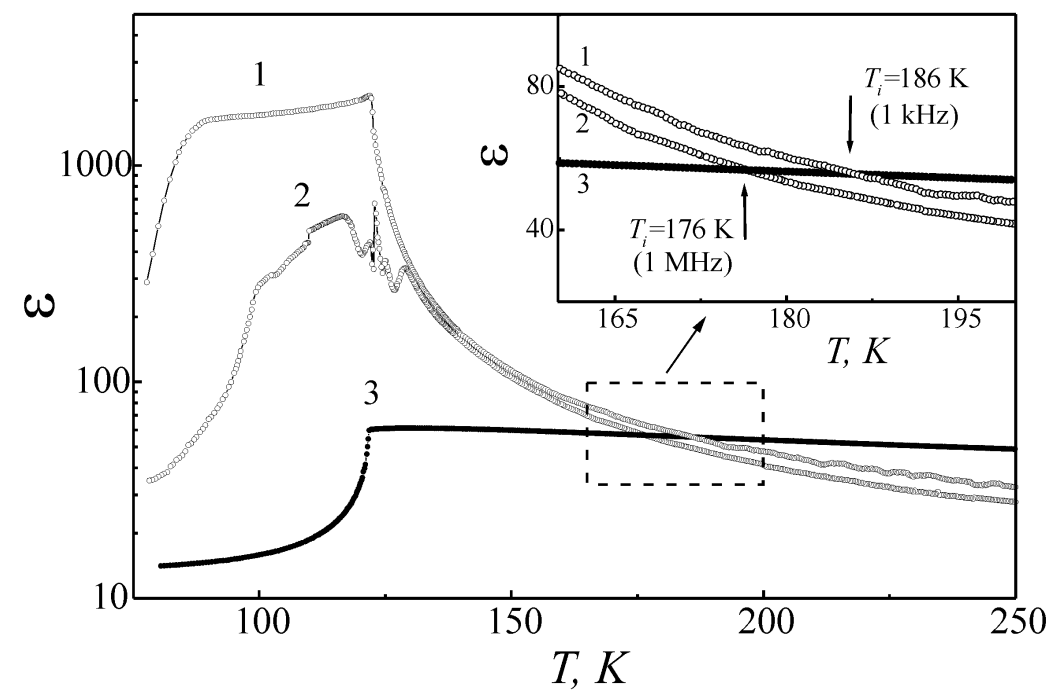

Figure 1. Temperature dependences of the longitudinal dielectric permeability at the frequency of $1 \mathrm{kHz}(1)$ and $1 \mathrm{MHz}(2)$ and transverse permeability (3) of the KDP crystal.

At room temperature the transverse dielectric permeability value is higher than the longitudinal one (see figure 1). The temperature decrease results in the increase of both values. However, the longitudinal dielectric permeability undergoes essential anomalous changes, its value sharply increasing while approaching the phase transition point. Therefore, at the temperature $T_{i}=186 \mathrm{~K}(f=1 \mathrm{kHz})$ the longitudinal and transverse dielectric permeability values become equal. The isotropic point temperature at the measuring field frequency of $1 \mathrm{MHz}$ is $T_{i}=176 \mathrm{~K}$ (see the insert to figure 1). At the temperatures $T<T_{i}$ the longitudinal dielectric permeability value exceeds the transverse one.

The orientation dependence of the dielectric permeability, which is a tensor in an anisotropic crystal, is given by

$$
\varepsilon=\varepsilon_{i j} l_{i} l_{j}
$$

where $\varepsilon_{i j}$ are the components of the dielectric permeability tensor, $l_{i}, l_{j}$ are cosines of the angles between the direction in which the dielectric permeability is being determined, and the Cartesian coordinate axes corresponding to the tensor notation, respectively. Using equation (1), for tetragonal KDP and DKDP crystals, the cross-section of the dielectric permeability indicative surface by the $a b$ plane in the principal axes, is given by

$$
\varepsilon(\varphi)=\varepsilon_{a} \sin ^{2}(\varphi)+\varepsilon_{c} \cos ^{2}(\varphi),
$$

where $\varphi$ is the angle between the direction in which $\varepsilon$ is determined and the ferroelectric axis $c$. Using equation (2), the cross-sections of the KDP crystal dielectric permeability indicative surface by the $a b$ plane were built. The temperature transformation of these cross-sections in the vicinity of the isotropic point is shown in 


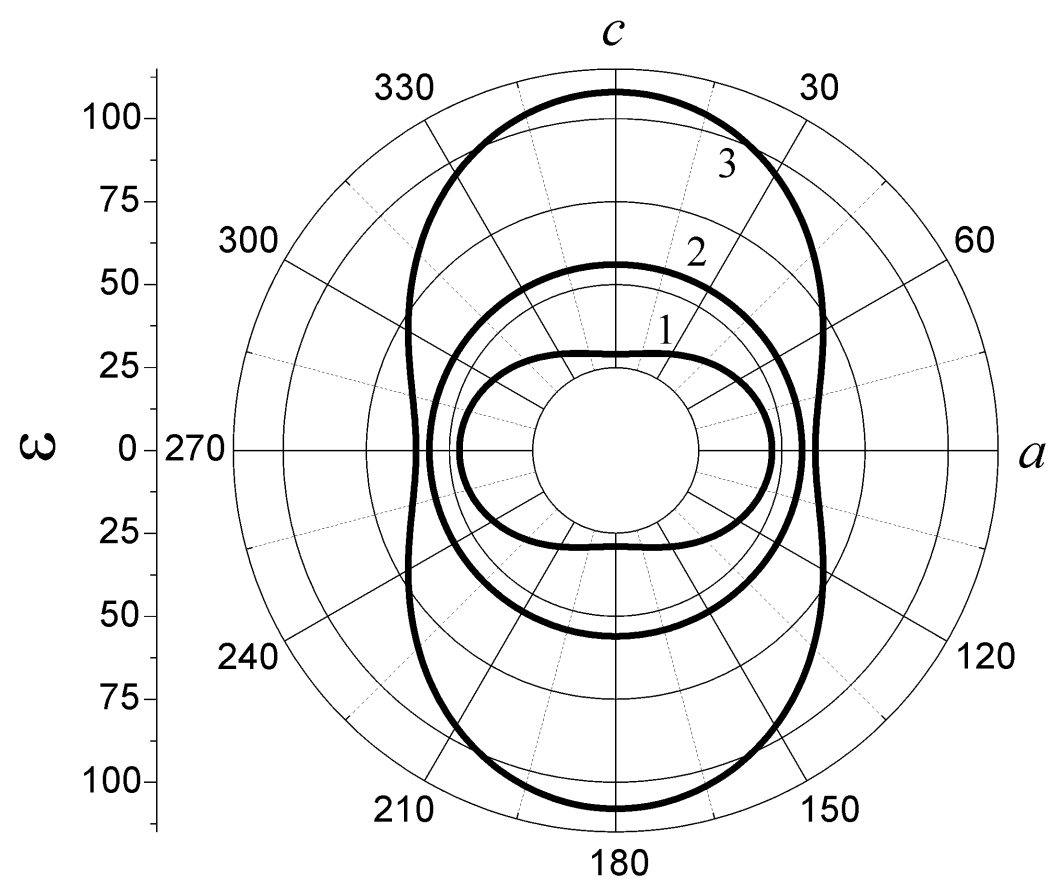

Figure 2. Temperature transformation of the cross-section of the dielectric permeability indicative surface by the $a c$ plane of the KDP crystal in the vicinity of the isotropic point: $1-T=275 \mathrm{~K}, 2-T=186 \mathrm{~K}, \quad 3-T=150 \mathrm{~K}$.

figure 2. As it is seen in the figure, at the temperature $T>T_{i}$ the major semiaxis of the dielectric permeability tensor is directed along the $a$ axis, at $T=T_{i}$ the longitudinal and transverse dielectric permeability values are equal and the indicative surface cross-section is circular, at $T<T_{i}$ the major semiaxis of the tensor is directed along the ferroelectric axis $c$.

The temperature dependences of the longitudinal and transverse dielectric permeability of DKDP crystals at atmospheric pressure at two frequencies of the measuring field are given in figure 3. As in the case of KDP crystals, there is no dispersion of transverse dielectric permeability in DKDP, and in the temperature dependence of the longitudinal dielectric permeability the piezoresonance effects are seen to be revealed at the frequency of $1 \mathrm{MHz}$ in the vicinity of the phase transition $\left(T_{\mathrm{c}}=221 \mathrm{~K}\right)$ (see curve 2). The specific feature of DKDP crystals is a considerable dispersion of the longitudinal dielectric permeability. Therefore, unlike KDP crystals, the isotropic point temperature strongly depends on the measuring field frequency. At the frequency of $1 \mathrm{kHz}$ the isotropic point is achieved at the temperature $T_{i}=300 \mathrm{~K}$, while at the frequency of $1 \mathrm{MHz}$ the $T_{i}$ value is $253 \mathrm{~K}$.

The behaviour of the temperature dependences of the longitudinal and transverse dielectric permeability under external hydrostatic pressure is illustrated in figure 4 (for KDP) and in figure 5 (for DKDP). The all-round pressure is seen to result in the decrease of the phase transition temperature in both crystals and in the shift of the $\varepsilon_{a}(T)$ and $\varepsilon_{c}(T)$ dependences towards lower temperatures. This leads to the isotropic point temperature decrease in these crystals. For KDP crystal, the pressure 


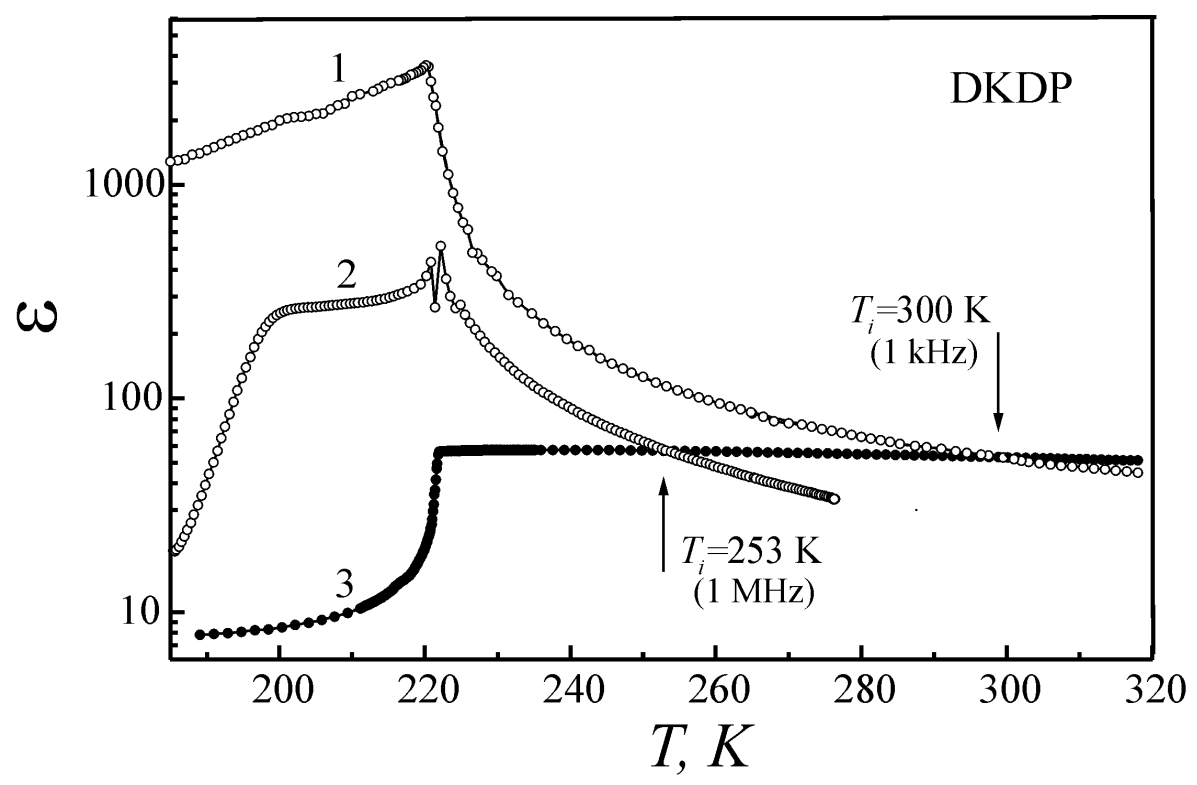

Figure 3. Temperature dependences of longitudinal dielectric permeability at the frequencies of $1 \mathrm{kHz}(1)$ and $1 \mathrm{MHz}(2)$ and transverse dielectric permeability (3) of the DKDP crystal.

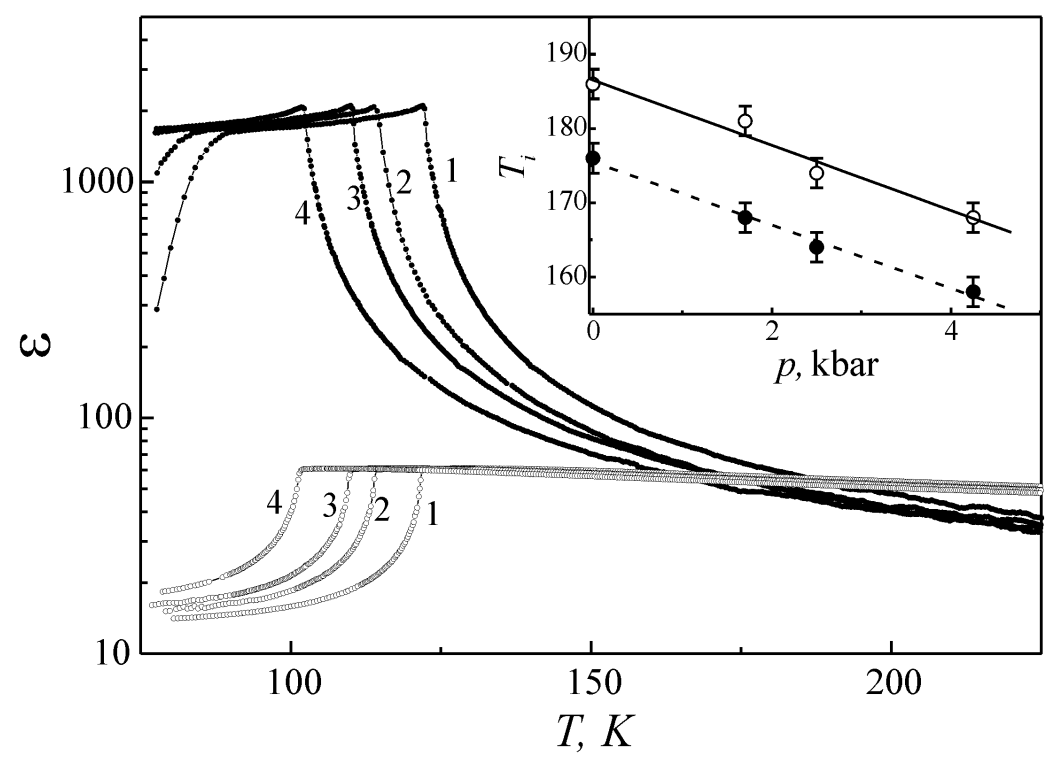

Figure 4. Temperature dependences of longitudinal (solid circles) and transverse (open circles) dielectric permeability of the KDP crystal at different values of the external hydrostatic pressure $p$, kbar: $1-0 ; 2-1.7 ; 3-2.5 ; 4-4.25$.

The insert shows the pressure dependence of the isotropic point temperature at the frequency of $1 \mathrm{kHz}$ (open circles) and $1 \mathrm{MHz}$ (solid circles). 


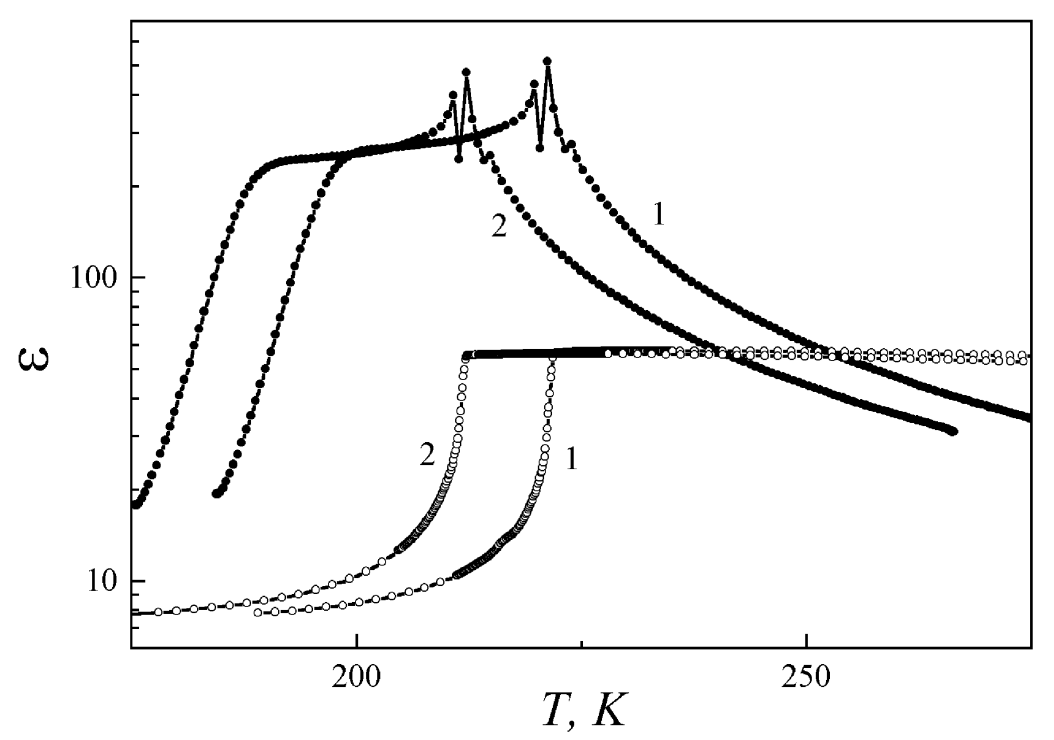

Figure 5. Temperature dependences of longitudinal (solid circles) and transverse (open circles) dielectric permeability of the DKDP crystal at different values of the external hydrostatic pressure $p$, kbar: $1-0 ; 2-4.1$.

coefficient of the isotropic point temperature is $\partial T_{i} / \partial p=-4.3 \mathrm{~K} / \mathrm{kbar}$ and does not depend on the measuring field frequency (see the insert to figure 4). For DKDP crystal $\partial T_{i} / \partial p=-2.9 \mathrm{~K} / \mathrm{kbar}$.

\section{Analysis}

Using the pseudospin formalism [11,12], the authors of [7] have obtained the relations, describing the temperature dependences of longitudinal and transverse dielectric permeability in the paraelectric phase of KDP crystals:

$$
\begin{aligned}
\chi_{c} & =\frac{2 N \mu_{1} \cdot \tanh \left(\frac{\Gamma}{T}\right)}{\Gamma-J(0) \tanh \left(\frac{\Gamma}{T}\right)}, \\
\chi_{a} & =\frac{N \mu_{2}^{2}}{\Gamma} \frac{\tanh \left(\frac{\Gamma}{T}\right)}{1+\frac{J(0)}{3 \Gamma} \tanh \left(\frac{\Gamma}{T}\right)},
\end{aligned}
$$

where $\Gamma$ is the tunnelling energy, $J(0)$ is the dipolar interaction energy in the meanfield approximation, $\mu_{1}$ is the dipolar moment along the $c$ axis, $\mu_{2}$ is the dipolar moment along the $a$ axis, $N=10^{22} \mathrm{~cm}^{-3}[7]$ is the hydrogenic bond concentration. Using equations (3), (4), one can obtain the value of temperature $T_{i}$, corresponding to the isotropic point $\left(\chi_{a}=\chi_{c}\right)$ :

$$
T_{i}=\Gamma / \operatorname{arcth} \frac{\Gamma\left(\mu_{2}^{2}-2 \mu_{1}^{2}\right)}{J(0)\left(\frac{2}{3} \mu_{1}^{2}+\mu_{2}^{2}\right)} .
$$


Thus, the isotropic point temperature position in this model is given by four values $J(0), \Gamma, \mu_{1}$ and $\mu_{2}$ which can be determined from the temperature dependences of the longitudinal and transverse dielectric permeability of KDP crystal.

The analysis of equation (4) shows the existence of a kink in the $\varepsilon_{a}(T)$ dependence, which is clearly revealed experimentally. The temperature of the kink point for the transverse dielectric permeability $T_{f}$ can be found from the condition $\partial^{2} \chi_{a} / \partial T^{2}=0$ :

$$
\tanh \left(\frac{\Gamma}{T_{f}}\right)=\frac{\left(3 T_{f}-J(0)\right) \Gamma}{3 \Gamma^{2}-J(0) T_{f}}
$$

Using equation (4) and taking into account the relationship between $J(0), \Gamma$ and the phase transition temperature $T_{\mathrm{c}}$, given by [7]

$$
\tanh \left(\frac{\Gamma}{T_{\mathrm{c}}}\right)=\frac{\Gamma}{J(0)},
$$

the unknown values of the tunnelling energy $\Gamma$ and dipolar interaction energy $J(0)$ can be determined knowing the experimentally obtained phase transition temperatures $T_{\mathrm{c}}$ and kink points in the $\varepsilon_{a}(T)$ dependence.

The unknown value of the dipolar moment along the $a$ axis $\mu_{2}$ is determined from the experimental value of transverse susceptibility in the kink point of $\varepsilon_{a}\left(T_{f}\right)$. By substituting equation (6) into equation (4) one obtains

$$
\varepsilon_{a}\left(T_{f}\right)=N \mu_{2}^{2} \frac{3 T_{f}-J(0)}{3 \Gamma^{2}-J(0)^{2} / 3} .
$$

The dipolar moment along the ferroelectric axis $\mu_{2}$ is determined based on the best fitting of the experimental dependence of the longitudinal dielectric permeability $\varepsilon_{c}(T)$ by equation (3). The experimental data for $T_{\mathrm{c}}, T_{f}, T_{i}^{\exp }, \varepsilon_{a}\left(T_{f}\right)$ and the calculated values of $J(0), \Gamma, \mu_{1}, \mu_{2}$ for KDP crystal at different hydrostatic pressure values are given in table 1 . In calculations, the regular part of the susceptibility $\chi_{0}=10 / 4 \pi[7]$ was taken into account. As one can see, for these crystals there is a good agreement between the experimentally obtained isotropic point temperature and the value calculated according to equation (5).

The unexpected changes in the theoretical parameters $\Gamma$ and $\mu_{1}$ with pressure were obtained (table 1). While the experimental behaviour of the dipolar moment could be related to the existence of the tricritical point in the phase $(p, T)$ diagram of the KDP crystal at $p \approx 2$ kbar [13], the decrease of $\Gamma$ with pressure disagrees with the common views [2].

The absence of the kink point at the temperature dependences of transverse dielectric permeability in the temperature range under investigation does not make it possible to use the above calculation techniques in analyzing the pressure behaviour of the isotropic point in DKDP crystals.

\section{Conclusion}

Temperature dependences of longitudinal and transverse dielectric permeability of KDP and DKDP crystals were studied at different values of hydrostatic pressure 
Table 1. The experimental data for $T_{\mathrm{c}}, T_{f}, T_{i}^{\exp }, \varepsilon_{a}\left(T_{f}\right)$ and the calculated values of $J(0), \Gamma, \mu_{1}, \mu_{2}$, for KDP crystal at different hydrostatic pressure values. The values of $\mu_{1}$ and $\mu_{2}$ are given in SGS units.

\begin{tabular}{|c|c|c|c|c|c|c|c|c|c|}
\hline$p, \mathrm{kbar}$ & $T_{\mathrm{c}}, \mathrm{K}$ & $T_{f}, \mathrm{~K}$ & $\varepsilon_{a}\left(T_{f}\right)$ & $J(0), \mathrm{K}$ & $\Gamma, \mathrm{K}$ & $\mu_{1}, 10^{-18}$ & $\mu_{2}, 10^{-18}$ & $T_{i}^{\text {theor }}, \mathrm{K}$ & $T_{i}^{\text {exp }}, \mathrm{K}$ \\
\hline 0 & 122.0 & 171.5 & 57.3 & 208 & 190 & 0.951 & 3.94 & 183 & 186 \\
\hline 1.7 & 114.3 & 162.5 & 57.0 & 196 & 180 & 0.969 & 3.82 & 178 & 181 \\
\hline 2.5 & 110.2 & 157.0 & 57.2 & 189 & 174 & 0.976 & 3.76 & 174 & 174 \\
\hline 4.25 & 106.5 & 147.5 & 56.8 & 177 & 163 & 0.950 & 3.62 & 164 & 168 \\
\hline
\end{tabular}

and at two measuring field frequencies $-1 \mathrm{kHz}$ and $1 \mathrm{MHz}$. The isotropic point temperature in KDP crystal at atmospheric pressure is $T_{i}=186 \mathrm{~K}$ at the measuring field frequency of $1 \mathrm{kHz}$, and $T_{i}=176 \mathrm{~K}$ at the frequency of $1 \mathrm{MHz}$. In DKDP crystals, the isotropic point is achieved at the temperatures $T_{i}=300 \mathrm{~K}(1 \mathrm{kHz})$ and $T_{i}=253 \mathrm{~K}(1 \mathrm{MHz})$. The hydrostatic pressure increase causes the decrease of the isotropic point temperature with the pressure coefficient $\partial T_{i} / \partial p=-4.3 \mathrm{~K} / \mathrm{kbar}$ for $\mathrm{KDP}$ and $\partial T_{i} / \partial p=-2.9 \mathrm{~K} / \mathrm{kbar}$ for DKDP. The pressure variation of the isotropic point temperature for both crystals is independent of the measuring field frequency.

The analysis of the experimental results has shown that in the framework of the tunnelling model in the molecular-field approximation, a satisfactory quantitative description of the temperature behaviour of the transverse dielectric permeability of the KDP crystal in the paraelectric phase can be obtained, as well as the temperature coordinate of the isotropic point and its dependence on the external pressure can be determined. However, unexpected pressure dependences of the parameters of the tunnelling model such as the tunnelling energy $\Gamma$ and dipolar moment $\mu_{1}$ were obtained. This is another evidence for the weakness of the tunnelling model for all-round description of pressure effects in KDP-type crystals. It has been shown in a number of papers [14-18] that an essential improvement of the theoretical description of the wide variety of the experimental data concerning the pressure effect on the physical properties of KDP-type crystals can be achieved with the account of short-range configurational interactions. Therefore, it seems important to perform further theoretical studies of the specific features of the temperature behaviour of longitudinal $\varepsilon_{c}$ and transverse $\varepsilon_{a}$ dielectric permeability in KDP-type crystals under external pressure, namely to analyze the obtained results in the framework of the proton ordering model with the account of short-range and long-range interactions and proton tunnelling at hydrogenic bonds in the four-particle cluster approximation $[19,20]$. Such studies could provide information on the physical grounds for the experimentally observed features at the $\varepsilon_{c}(T)$ and $\varepsilon_{a}(T)$ dependences discussed in the present work. 


\section{References}

1. Nelmes R.J., Tun Z., Kuhs W.F. // Ferroelectrics, 1987, vol. 71, p. 125.

2. Samara G.A. // Phys. Rev. Lett., 1971, vol. 27, p. 103.

3. Kuramoto K. // JPSJ, 1987, vol. 56, No. 5, p. 1859.

4. Nakamura E., Kuramoto K. // JPSJ, 1988, vol. 57, No. 6, p. 2182.

5. Blinc R., Svetina S., Žekš B. // Solid State Commun., 1972, vol. 10, p. 387.

6. Braeter H., Plakida N.M., Windsch W. // Solid State Commun., 1989, vol. 69, No. 3, p. 289.

7. Havlin S., Litov E., Uehling E.A. // Phys. Rev. B, 1974, vol. 9, No. 3, p. 1024.

8. Gesi K., Ozawa K. // JPSJ, 1984, vol. 53, No. 12, p. 4405.

9. Bush C. // Helv. Phys. Acta, 1938, vol. 11, p. 269.

10. Levitskii R.R., Slivka A.G., Moina A.P., Lukach P.M., Guivan A.M. // Journal of Physical Studies, 2002, vol. 6, No. 2, p. 197.

11. Gennes P.G. // Solid State Commun., 1963, vol. 1, p. 138.

12. Tokunaga M., Matsubara T. // Prog. Teor. Phys., 1968, vol. 35, p. 381.

13. Schmidt V.H., Western A.B., Baker A.G. // Phys. Rev. Lett., 1978, vol. 37, p. 839.

14. Stasyuk I.V., Biletskii I.N. // Bull. Acad. Sci. USSR, Phys. Ser., 1983, vol. 4, p. 79.

15. Stasyuk I.V., Levitskii R.R., Zachek I.R., Moina A.P., Duda A.S. // Condens. Matter Phys., 1996, iss. 8, p. 129.

16. Stasyuk I.V., Levitskii R.R., Moina A.P. et al. // J. Phys. Stud., 1999, vol. 3, p. 502.

17. Stasyuk I.V., Levitskii R.R., Moina A.P., Lisnii B.M. // Ferroelectrics, 2001, vol. 254, p. 213.

18. Stasyuk I.V., Levitskii R.R., Zachek I.R., Duda A.S. // Condens. Matter Phys., 2001, vol. 4, No. 3, p. 553.

19. Stasyuk I.V., Levitskii R.R., Moina A.P., // Phys. Rev. B, 1999, vol. 59, No. 13, p. 8530 .

20. Stasyuk I.V., Levitskii R.R., Zachek I.R, Moina A.P. // Phys. Rev. B, 2000, vol. 62, No. 10, p. 6198. 


\title{
Вплив температури і тиску на анізотропію діелектричної проникності кристалів KDP і DKDP
}

\author{
В.М.Кедюлич, О.Г.Сливка, О.І.Герзанич, Г.М.Гуйван, \\ П.М.Лукач
}

Ужгородський національний університет, 88000 Ужгород, вул. Волошина, 32

Отримано 24 жовтня 2002 р., в остаточному вигляді - 4 квітня 2003 p.

Проведено дослідження температурних залежностей повздовжньої та поперечної діелектричної проникності кристалів KDP та DKDP при різних величинах гідростатичного тиску з метою визначення баричної поведінки температури ізотропної точки для цих кристалів. Температура ізотропної точки в кристалах KDP при атмосферному тиску становить $T_{i}=186 \mathrm{~K}$ при частоті вимірювального поля 1 кГц та $T_{i}=176 \mathrm{~K}$ на частоті 1 МГц. В кристалах DKDP ізотропна точка реалізується при температурах $T_{i}=300 \mathrm{~K}$ ( 1 кГц) та $T_{i}=253 \mathrm{~K}$ ( 1 МГц). Збільшення гідростатичного тиску приводить до пониження температури ізотропної точки з баричними коефіцієнтами $\partial T_{i} / \partial p=-4.3 \mathrm{~K} /$ кбар для KDP та $\partial T_{i} / \partial p=-2.9 \mathrm{~K} /$ кбар для DKDP. Аналіз експериментальних результатів в рамках псевдоспінового формалізму Блінца-Жекша показав, що існує добре узгодження між розрахованою та експериментально визначеною температурою ізотропної точки для кристалів KDP.

Ключові слова: сегнетоелектрики, діелектрична проникність, гідростатичний тиск, ізотропна точка

PACS: 77.80.Bh, 77.22.Ch, 77.84.Fa 